\title{
Proximity to Industrial Food Animal Production and Asthma Exacerbations in Pennsylvania, 2005-2012
}

\author{
Sara G. Rasmussen ${ }^{1}$, Joan A. Casey ${ }^{2}$, Karen Bandeen-Roche ${ }^{3}$ and Brian S. Schwartz ${ }^{1,4,5, *}$ \\ 1 Department of Environmental Health and Engineering, Johns Hopkins Bloomberg School of Public Health, \\ Baltimore, MD 21205, USA; srasmus7@jhu.edu \\ 2 Department of Environmental Science, Policy \& Management, University of California, Berkeley, \\ Berkeley, CA 94720, USA; joanacasey@berkeley.edu \\ 3 Department of Biostatistics, Johns Hopkins Bloomberg School of Public Health, Baltimore, MD 21205, USA; \\ kbandee1@jhu.edu \\ 4 Department of Epidemiology and Health Services Research, Geisinger Health System, \\ Danville, PA 17822, USA \\ 5 Department of Medicine, Johns Hopkins School of Medicine, Baltimore, MD 21205, USA \\ * Correspondence: bschwar1@jhu.edu; Tel.: +1-410-955-4158
}

Academic Editor: Paul B. Tchounwou

Received: 10 March 2017; Accepted: 30 March 2017; Published: 31 March 2017

\begin{abstract}
The research on industrial food animal production (IFAP) and asthma exacerbations in the United States has relied on small sample sizes and/or self-reported outcomes. We assessed associations of proximity to large-scale and densely stocked swine and dairy/veal IFAP with three types of asthma exacerbations: hospitalizations, emergency encounters, and oral corticosteroid (OCS) medication orders from Geisinger Clinic in Pennsylvania. We used a diagnosis code (International Classification of Diseases, 9th Revision, Clinical Modification code 493.x) and medication orders from electronic health records to identify these exacerbations among asthma patients $(n=35,269)$ from 2005-2012. We compared residential proximity to swine or dairy/veal IFAP (dichotomized as $<3$ miles $(4.8 \mathrm{~km})$ or $\geq 3$ miles) among asthma patients with and without exacerbations and estimated odds ratios using multilevel logistic regression. In adjusted models, proximity to IFAP was associated (odds ratio (95\% confidence interval)) with OCS orders (1.11 (1.04-1.19)) and hospitalizations (1.29 (1.15-1.46)), but not emergency encounters (1.12 (0.91-1.37)). This study contributes to growing evidence that IFAP may impact health, in this case clinically-documented asthma exacerbations. No prior study has evaluated the association of IFAP and clinically-documented asthma exacerbations in the United States.
\end{abstract}

Keywords: asthma; asthma exacerbation; concentrated animal feeding operation (CAFO)

\section{Introduction}

Living or attending school near industrial food animal production (IFAP)—-large-scale, densely stocked, and highly specialized farms—-has been linked to adverse health outcomes [1]. Of particular concern are asthma exacerbations. Asthma is a chronic condition characterized by recurring symptoms (including cough, wheezing, shortness of breath, and chest tightness) that affects over 25 million people in the United States [2,3]. IFAP facilities are a source of odors and several air pollutants, including particulate matter, hydrogen sulfide, and ammonia [4], and these air pollutants and odors have been associated with asthma exacerbations [2,5,6]. Most, but not all, studies on IFAP and asthma exacerbations have found IFAP to be a risk factor for decreased lung function and asthma symptoms [1,5,7-15]. However, the research on IFAP and asthma exacerbations in the United States has relied on small sample sizes and/or self-reported outcomes [5,7-10], and studies that have used 
clinically-documented events, from the Netherlands, reported no association or a protective association of IFAP and asthma exacerbations [14-16]. In this study, we used electronic health record (EHR) data from the Geisinger Clinic, located in central and northeastern Pennsylvania, to conduct a case-control study of the association between proximity to swine or dairy/veal IFAP and clinically-documents asthma exacerbations in a population of patients with asthma.

\section{Materials and Methods}

\subsection{IFAP Data and Study Population}

Swine and dairy/veal IFAP were identified in nutrient management plans from the Pennsylvania Department of Environmental Protection and County Conservation Districts in the Geisinger Clinic's service area and adjacent counties, as described in a prior study [4]. In Pennsylvania, the Department of Environmental Protection and County Conservation Districts regulate IFAP, both concentrated animal feeding operations (CAFOs, defined as operations with $>1000$ animal equivalent units (AEUs; 1 AEU $=1000 \mathrm{lbs}$ or $454 \mathrm{~kg}$ )) and concentrated animal operations (CAOs, defined as $>2$ AEUs/acre) under Act 38. Act 38 requires operators to produce nutrient management plans every two years. We located swine and dairy/veal IFAP in the Geisinger Clinic's service area and adjacent counties using these plans and assigned each a latitude and longitude based on the location of operation's center [4].

The study population consisted of primary patients with asthma, and we identified the study population from the Geisinger Clinic population, which is representative of the general population in the region, using methods described in a prior study [17]. Briefly, we considered patients with at least two encounters with asthma diagnoses on different days (using International Classification of Diseases, 9th Revision, Clinical Modification code 493.x), or at least one encounter with an asthma diagnosis and at least one medication order with an asthma diagnosis on different days, to be patients with asthma [18]. Patients were geocoded to their home addresses using ArcGIS Advanced for Desktop, v10.1 (Esri, Redlands, CA, USA) and restricted the study population to the Geisinger Clinic's service area and adjacent counties (Figure 1). We identified the following asthma exacerbations among the study population in the EHR: hospitalizations (2005-2012), emergency encounters (2005-2012), and new oral corticosteroid (OCS) orders (2008-2012; OCS orders were only consistently captured in the EHR from 2008 and on). We used both primary and secondary diagnosis codes for asthma for hospitalizations and emergency encounters because we were unable to differentiate between asthma exacerbations that led to hospitalizations and asthma exacerbations that occurred while patients were hospitalized. We identified new OCS medication orders for asthma exacerbations by excluding standing orders and requiring that the outpatient visit reason or medication order diagnosis was asthma-related [17]. The study was approved by the Geisinger Institutional Review Board (approval number 2013-0114, with an Institutional Review Board authorization agreement with Johns Hopkins Bloomberg School of Public Health). 


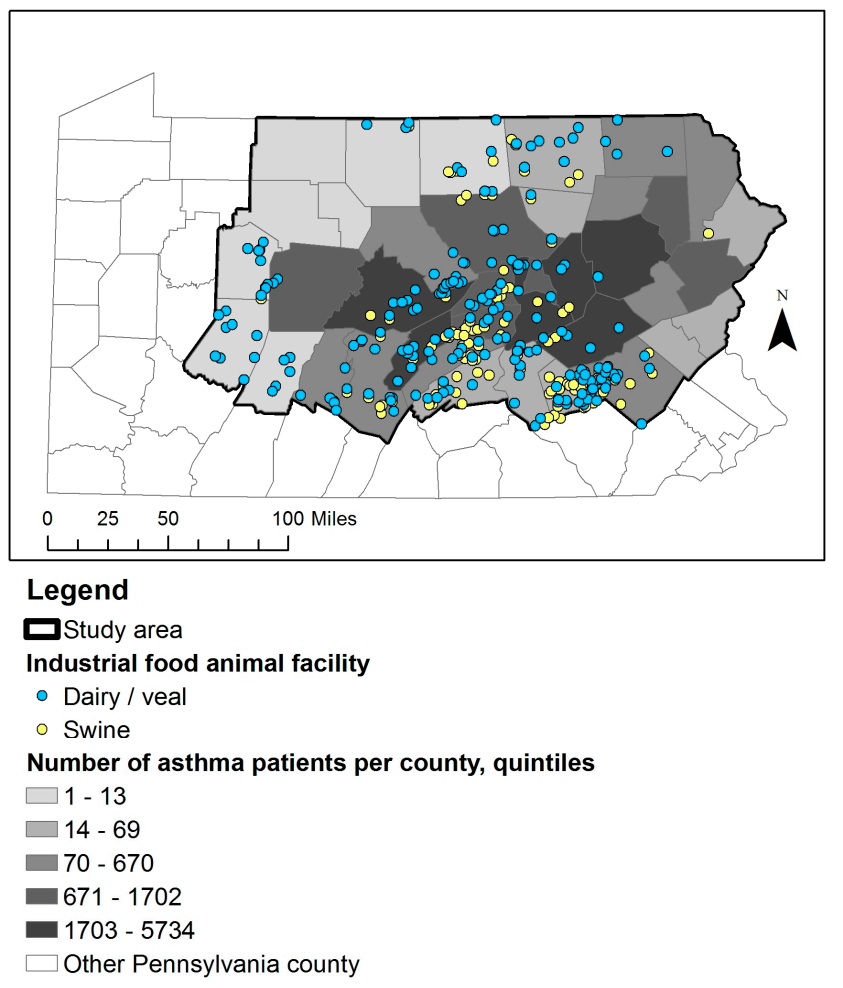

Figure 1. The location of swine and dairy/veal industrial food animal production facilities and the residential location of Geisinger Clinic asthma patients.

\subsection{Comparison Subjects and Matching}

For each type of asthma exacerbation, we compared asthma patients with at least one exacerbation of that type during the study period to comparison subjects, who were asthma patients with no or less severe exacerbations (OCS order $<$ emergency encounter $<$ hospitalization) during the study period. We frequency-matched comparison subjects to cases on age category $(5-12,13-18,19-44,45-61,62-74$, $75+$ years), sex (male, female), and year of event. For cases, the date of their first event was used as the year for frequency-matching and as the date to assign time-varying covariates. For comparison subjects, we needed a date for frequency matching by year and to assign time-varying covariates, so we used randomly selected a date on which the patient had contact with the health system. Hospitalization cases were matched to comparison subjects at 1:3, emergency department cases were matched at 1:5, and OCS cases were matched at 1:1.

\subsection{Statistical Analysis}

For each outcome, we evaluated unadjusted and adjusted multilevel logistic regression models with a random intercept for community to account for patient clustering within communities (in cities, census tracts; in townships and boroughs, minor civil divisions). Proximity to IFAP was defined as a swine or dairy /veal operation within a three mile $(4.8 \mathrm{~km})$ buffer of the patient's residence; this distance was chosen based on a prior study [9]. Covariates in the adjusted model included those created using the EHR: age category, year, sex, self-reported race/ethnicity (white, black, Hispanic, other/missing; race/ethnicity is a well-documented confounder in asthma studies [2]), season, smoking status, family history of asthma, overweight/obesity (using body mass index (BMI) percentile for children and BMI $\left(\mathrm{kg} / \mathrm{m}^{3}\right)$ for adults [19]), Medical Assistance (a means tested program that is an indicator of low family socioeconomic status), and type 2 diabetes; and those created using patients' geocoded coordinates: distance to nearest major and minor road and community socioeconomic deprivation (CSD) $[4,17,20,21]$. Because distance from patient address to the closer of the two major Geisinger 
hospitals, where $96 \%$ of asthma hospitalizations and $85 \%$ of asthma emergency encounters took place, was a potential confounding variable, it was included in the hospitalization and emergency encounter models. Distance to hospital was not included in the OCS model, as OCS orders were handled at outpatient locations and over the phone. Continuous covariates were included with linear and quadratic terms to allow for non-linearity.

\subsection{Sensitivity Analyses}

We conducted several sensitivity analyses. Because we were interested in effect modification by age, we evaluated whether associations between IFAP and asthma exacerbations were different among children and adults by adding a cross-product of proximity to IFAP and an indicator for childhood age (5-18 years) to the final model for each outcome. To evaluate the impact of including patients in urban areas, we completed a sensitivity analysis that excluded patients in cities. We evaluated associations among patients who had more than one exacerbation of a given type by repeating the primary analysis only including cases with more than one of a given type of exacerbation. Because of concern about confounding by distance to hospital, in a sensitivity analysis for the hospitalization and emergency department outcomes, we individually matched (1:1) cases to comparison subjects on age, sex, and distance to hospital in five mile increments. Because of the individual matching, for this analysis we evaluated unadjusted and adjusted conditional logistic regressions, which included the same covariates as in the primary analysis. To evaluate the impact of using patients with asthma exacerbations less severe than the cases as comparison subjects on our associations, or each outcome, we completed a sensitivity analysis in which asthma patients with that type of exacerbation were compared to patients with no asthma exacerbations of any type during the study period, and we then evaluated associations using crude and adjusted logistic regressions.

\section{Results}

\subsection{Description of Study Population}

We identified 35,269 patients with asthma in the study area. The study population was $92 \%$ white, 58\% female, had a median age of 31 years in 2012, and 59, 30, and $11 \%$ of the population lived in townships, boroughs, and cities, respectively. The hospitalization analysis included 3552 cases and 10,640 comparison subjects, the emergency encounter analysis included 1445 cases and 7225 comparison subjects, and the OCS analysis included 13,137 cases and 13,044 comparison subjects. Cases for each of the three outcomes were more likely than comparison subjects to have a family history of asthma, be current smokers, have Medical Assistance, be obese, and live in communities in the highest quartile of CSD (Tables 1 and 2). Cases in the hospitalization and emergency analyses, but not the OCS analysis, were less likely to be white non-Hispanic and more likely to live closer to major and minor roads. We identified 123 swine and 203 dairy/veal operations, and $8399(24 \%)$ patients lived within 3 miles of one of these (Figure 1).

Table 1. Descriptive statistics of cases and comparison subject characteristics by exacerbation type.

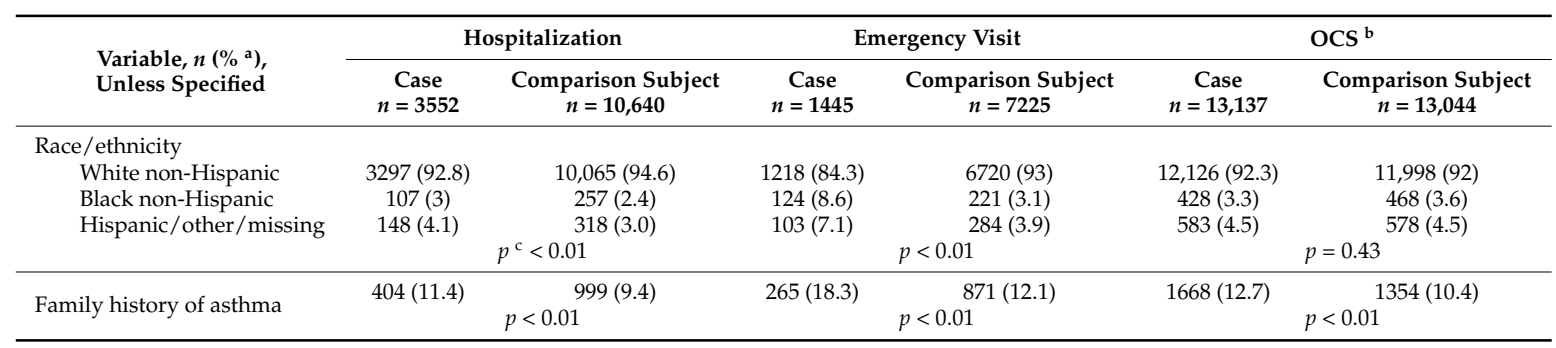


Table 1. Cont

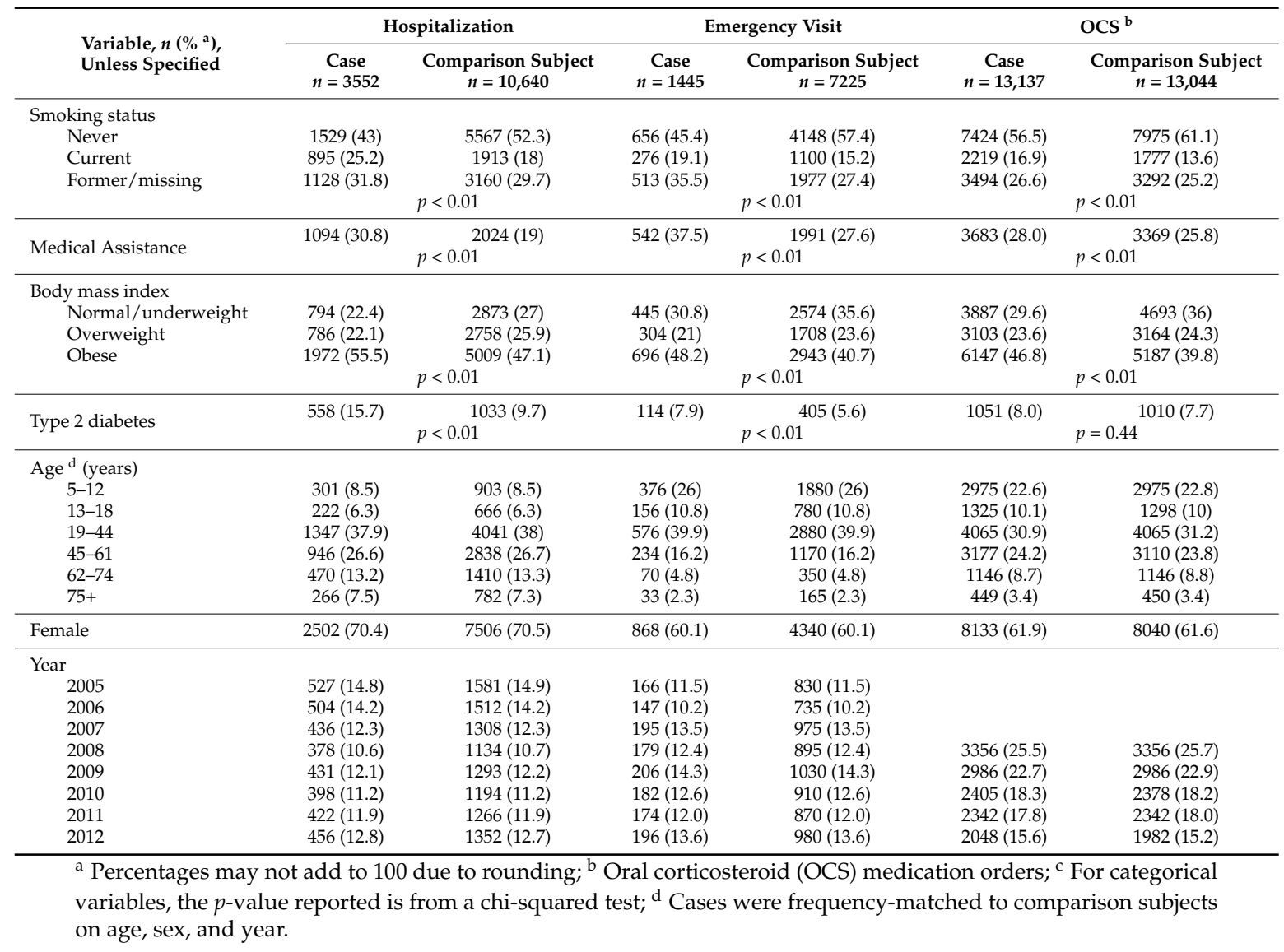

Table 2. Place-level descriptive statistics of cases and comparison subjects by exacerbation type.

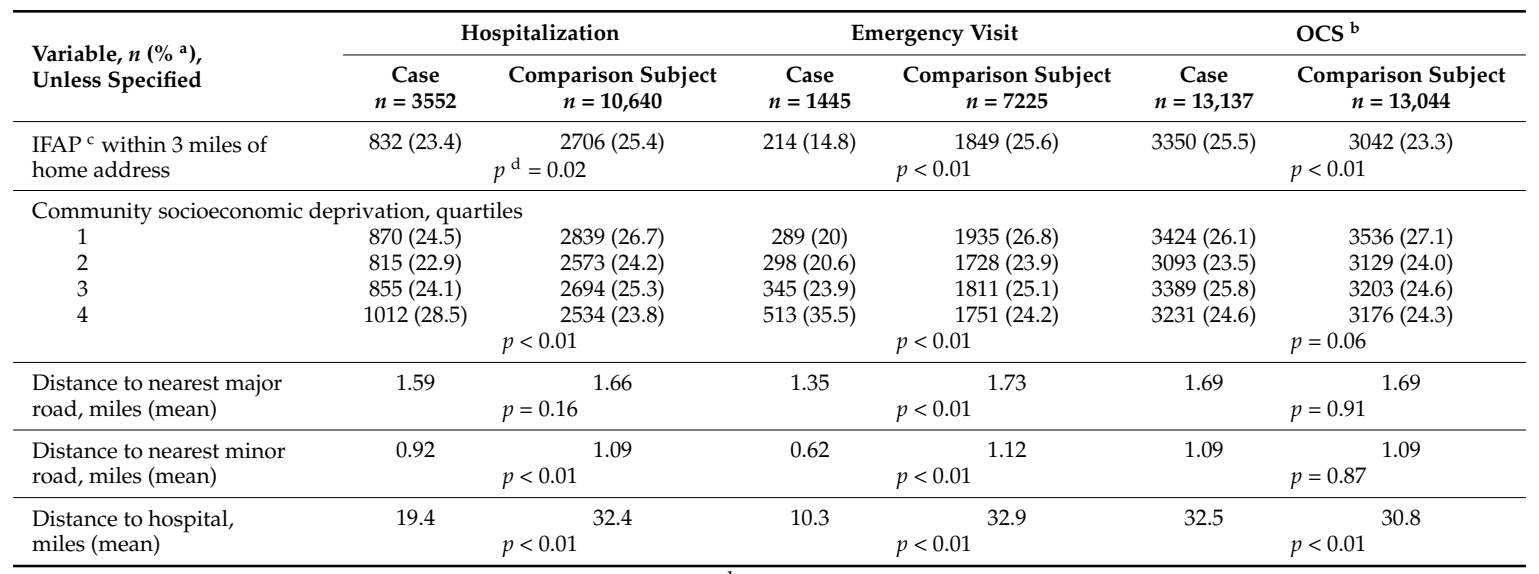

${ }^{a}$ Percentages may not add to 100 due to rounding; ${ }^{\mathrm{b}}$ Oral corticosteroid (OCS) medication orders; ${ }^{\mathrm{c}}$ Industrial food animal production; ${ }^{\mathrm{d}}$ For continuous variables, the $p$-value reported is from a $t$-test. For categorical variables, the $p$-value reported is from a chi-squared test.

\subsection{Association of IFAP and Asthma Exacerbations}

In unadjusted models, proximity to IFAP was not associated with hospitalizations (odds ratio $\mathrm{OR}=1.11,95 \% \mathrm{CI}: 0.97-1.27)$ or emergency encounters (OR $=0.90,95 \% \mathrm{CI}: 0.70-1.16)$, but was associated with increased odds of OCS orders (OR $=1.11,95 \%$ CI: 1.03-1.19). After distance to hospital was added to the model, proximity to IFAP was associated with increased odds in the hospitalization 
model and was not associated in the emergency encounters model. Adding the remaining covariates did not substantially change the associations (Table 3).

Table 3. Associations of proximity to industrial food animal production (defined as a facility within 3 miles of home address) and asthma exacerbation outcomes.

\begin{tabular}{|c|c|c|c|}
\hline \multirow{2}{*}{ Variable $\left(95 \% \mathrm{CI}^{\mathrm{a}}\right)$} & \multicolumn{3}{|c|}{ Outcome } \\
\hline & Asthma Hospitalizations ${ }^{b}$ & $\begin{array}{l}\text { Asthma Emergency } \\
\text { Department Visits }\end{array}$ & $\begin{array}{l}\text { New Asthma OCS } \\
\text { Orders }^{\mathrm{d}}\end{array}$ \\
\hline $\begin{array}{l}\text { Proximity to industrial food } \\
\text { animal production } \mathrm{e}^{\mathrm{e}}\end{array}$ & $1.29(1.15-1.46)$ & $1.12(0.91-1.37)$ & $1.11(1.04-1.19)$ \\
\hline \multicolumn{4}{|l|}{ Race/ethnicity (ref: white non-Hispanic) } \\
\hline Black non-Hispanic & $1.05(0.81-1.36)$ & $1.86(1.4-2.46)$ & $0.84(0.73-0.97)$ \\
\hline Hispanic & $1.23(0.99-1.54)$ & $1.47(1.11-1.93)$ & $0.95(0.84-1.08)$ \\
\hline Family history of asthma (ref: no) & $1.27(1.11-1.45)$ & $1.68(1.4-2.01)$ & $1.27(1.17-1.37)$ \\
\hline \multicolumn{4}{|l|}{ Smoking status (ref: never) } \\
\hline Current & $1.45(1.3-1.62)$ & $1.35(1.12-1.63)$ & $1.39(1.29-1.5)$ \\
\hline Former & $1.18(1.08-1.3)$ & $1.45(1.25-1.68)$ & $1.15(1.08-1.22)$ \\
\hline Medical Assistance (ref: no) & $1.87(1.69-2.07)$ & $1.32(1.13-1.54)$ & $1.06(0.998-1.13)$ \\
\hline \multicolumn{4}{|l|}{$\begin{array}{l}\text { Body mass index (ref: } \\
\text { normal/underweight) }\end{array}$} \\
\hline Overweight & $1.07(0.95-1.21)$ & $1.07(0.89-1.28)$ & $1.24(1.16-1.33)$ \\
\hline Obese & $1.36(1.22-1.51)$ & $1.3(1.11-1.52)$ & $1.53(1.43-1.62)$ \\
\hline Type 2 diabetes (ref: no) & $1.63(1.43-1.85)$ & $1.29(0.99-1.69)$ & $0.93(0.84-1.03)$ \\
\hline \multicolumn{4}{|l|}{$\begin{array}{l}\text { Community socioeconomic deprivation } \\
\text { (ref: quartile 1) }\end{array}$} \\
\hline Quartile 2 & $0.97(0.83-1.13)$ & $1.28(1.01-1.63)$ & $0.99(0.91-1.08)$ \\
\hline Quartile 3 & $0.97(0.83-1.14)$ & $1.41(1.10-1.82)$ & $1.01(0.93-1.11)$ \\
\hline Quartile 4 & $0.94(0.79-1.12)$ & $1.41(1.10-1.82)$ & $0.98(0.89-1.08)$ \\
\hline \multicolumn{4}{|l|}{$\begin{array}{l}\text { Distance to nearest major arterial road, } \\
\text { z-transformed }\end{array}$} \\
\hline z-transformed & $0.94(0.84-1.04)$ & $1.10(0.93-1.31)$ & $0.97(0.91-1.03)$ \\
\hline squared & $1.07(1.02-1.12)$ & $1.04(0.97-1.12)$ & $1.02(0.99-1.05)$ \\
\hline \multicolumn{4}{|l|}{ Distance to nearest minor arterial road } \\
\hline $\begin{array}{l}\text { Z-transformed } \\
\text { squared }\end{array}$ & $\begin{array}{c}1.08(0.97-1.19) \\
0.998(0.95-1.05)\end{array}$ & $\begin{array}{l}1.03(0.87-1.22) \\
0.89(0.79-1.003)\end{array}$ & $\begin{array}{c}0.98(0.92-1.04) \\
1.003(0.98-1.03)\end{array}$ \\
\hline \multicolumn{4}{|l|}{ Distance to nearest Geisinger hospital } \\
\hline $\mathrm{z}$-transformed & $0.46(0.42-0.51)$ & $0.10(0.08-0.13)$ & \\
\hline squared & $1.14(1.07-1.21)$ & $1.35(1.09-1.66)$ & $\mathrm{f}$ \\
\hline
\end{tabular}

${ }^{a}$ Confidence interval; ${ }^{b}$ Multilevel models with a random intercept for community, adjusted for race/ethnicity (white, black, Hispanic, other), family history of asthma (yes, no), smoking status (never, former, current, missing), Medical Assistance (yes vs. no), overweight/obesity (normal, body mass index (BMI) $<$ 85th percentile or BMI $<25 \mathrm{~kg} / \mathrm{m}^{2}$; overweight, BMI $=85$ th $<95$ th percentile or BMI $=25<30 \mathrm{~kg} / \mathrm{m}^{2}$; obese, BMI $\geq 95$ th percentile or BMI $\geq 30 \mathrm{~kg} / \mathrm{m}^{2}$, for children and adults, respectively; BMI missing), type 2 diabetes (yes vs. no), community socioeconomic deprivation (quartiles), distance to nearest major and minor arterial road (truncated at the 98th percentile, meters, $z$-transformed), squared distance to nearest major and minor arterial road (truncated at the 98th percentile, meters, z-transformed), distance to nearest Geisinger hospital (truncated at the 98th percentile, kilometers, z-transformed), squared distance to nearest Geisinger hospital (truncated at the 98th percentile, kilometers, z-transformed), age category (5-12, 13-18, 19-44, 45-61, 62-74, 75+ years), sex (male, female), and year of event $(2005,2006,2007,2008,2009,2010,2011,2012)$; ${ }^{c}$ Oral corticosteroid; ${ }^{d}$ Multilevel model with a random intercept for community, adjusted for race/ethnicity (white, black, Hispanic, other), family history of asthma (yes, no), smoking status (never, former, current, missing), Medical Assistance (yes vs. no), overweight/obesity (normal, body mass index $(\mathrm{BMI})<85$ th percentile or BMI $<25 \mathrm{~kg} / \mathrm{m}^{2}$; overweight, $\mathrm{BMI}=85 \mathrm{th}<95$ th percentile or BMI $=25<30 \mathrm{~kg} / \mathrm{m}^{2}$; obese, BMI $\geq 95$ th percentile or BMI $\geq 30 \mathrm{~kg} / \mathrm{m}^{2}$, for children and adults, respectively; BMI missing), type 2 diabetes (yes vs. no), community socioeconomic deprivation (quartiles), distance to nearest major and minor arterial road (truncated at the 98 th percentile, meters, z-transformed), squared distance to nearest major and minor arterial road (truncated at the 98th percentile, meters, z-transformed), age category (5-12, 13-18, 19-44, 45-61, 62-74, 75+ years), sex (male, female), and year of event (2008, 2009, 2010, 2011, 2012); ${ }^{\mathrm{e}}$ Within 3 miles of home address; $\mathrm{f}$, Distance to hospital was not included in this model.

\subsection{Results of Sensitivity Analyses}

The $p$-value of the cross-product of proximity to IFAP and an indicator for childhood age were 0.53 , 0.73 , and 0.82 for the hospitalization, emergency department, and OCS analyses, respectively, indicating that associations in children and in adults were similar. The odds ratios from the sensitivity analysis that excluded patients in cities (for hospitalizations, OR $=1.29,95 \% \mathrm{CI}$ : $1.14-1.46$; for emergency 
encounters, $\mathrm{OR}=1.09,95 \%$ CI: $0.89-1.34$; and for OCS orders, $\mathrm{OR}=1.12,95 \%$ CI: $1.04-1.20$ ) were similar to those in the primary analysis. In the sensitivity analysis that included cases with more than one of a given type of event, we found similar results as in the primary analysis (for hospitalizations, $\mathrm{OR}=1.39,95 \% \mathrm{CI}: 1.09-1.76$; for emergency encounters, OR $=1.12,95 \% \mathrm{CI}$ : $0.91-1.37$; and for OCS orders, $\mathrm{OR}=1.14,95 \% \mathrm{CI}: 1.02-1.27)$. In the sensitivity analysis that individually matched cases to comparison subjects on age, sex, and distance to hospital, in adjusted models, associations were similar to those from the primary analysis for hospitalizations (OR $=1.24,95 \%$ CI: 1.09-1.40) and for emergency encounters ( $\mathrm{OR}=1.07,95 \% \mathrm{CI}$ : 0.86-1.33). In the sensitivity analysis that used patients with no asthma exacerbations during the study period as comparison subjects, associations were similar to the primary analysis for hospitalizations ( $\mathrm{OR}=1.29,95 \% \mathrm{CI}$ : 1.13-1.46) and stronger though still not statistically significant for emergency encounters (OR $=1.19,95 \%$ CI: $0.97-1.46)$.

\section{Discussion}

We evaluated associations of IFAP with three kinds of clinically-documented asthma exacerbations, and conducted a number of sensitivity analyses, in a large population of asthma patients in a region with many IFAP facilities. We found $11 \%$ and $29 \%$ increased odds of OCS orders and asthma hospitalizations, respectively, among asthma patients living within 3 miles of IFAP, compared to living farther away. We did not observe effect modification by childhood age. We found similar results using individual matching on distance to hospital, and using patients with no asthma exacerbations during the study period as the comparison group.

Our study found that distance to hospital was an important confounder in the hospitalization analysis. A study from the Netherlands found that proximity to livestock farms $(<500 \mathrm{~m}$ from home address) was negatively associated with the number of patient contacts with general practitioners (including encounters, home visits, and telephone consultations), but in contrast to our study, their association was unchanged when distance to general practice was added to the model [16].

We report different results than two prior studies from the Netherlands that used clinically-documented asthma (as opposed to self-reported) to assess the association of IFAP and asthma. The first study evaluated asthma prevalence, not exacerbations, so it is not relevant to our findings [14]. The other study concluded that proximity to IFAP was not associated with asthma exacerbations [15]. They found no association of distance to nearest swine or poultry farm with asthma exacerbations, as measured by an increase in the dose or a new medication order for asthma medications. In contrast to that study, we found an increased risk of new OCS orders for asthma and for asthma hospitalizations among asthma patients living close to swine or dairy/veal IFAP compared to farther away.

Our study had limitations. The buffer proximity approach treated swine and dairy/veal facilities as the same, though emissions may differ between the two, and did not incorporate animal count, IFAP building characteristics, or wind direction. Furthermore, we did not have information on poultry IFAP and we did not take air samples. Proximity was based on distance from residential address (ascertained in 2013) to closest IFAP operation, so it might misclassify exposures at school or work, or if the patient had recently moved, though an analysis in a prior study of this population indication low residential mobility [8]. We did not have information on study participants' housing conditions, which could contribute to asthma exacerbations. We did not ascertain events that occurred outside the Geisinger system. The EHR only captures events for which patients seek care, so we do not have data on asthma symptoms that patients could treat on their own without medical care. We only collected information on IFAP in 2010 and 2011, and we assumed facilities were in the same location for the entire study period. However, we verified the locations of a random sample of 20 IFAP in Google Earth's historical aerial imagery, and all were present in the images since at least 2005, so we believe this was a reasonable assumption. Strengths of this study included a large sample size consisting of both children and adults. We incorporated both swine and dairy/veal IFAP, unlike previous studies in the 
United States that only incorporated swine IFAP $[1,8,9]$. We used asthma exacerbations documented in an EHR instead of relying on self-reported outcomes [1,5,8], which can result in recall bias [22].

\section{Conclusions}

Our study observed an association of clinically-documented asthma exacerbations, a serious public health concern, in relation to IFAP in Pennsylvania. The finding is biologically plausible and was robust in a number of relevant sensitivity analyses.

Acknowledgments: This study was funded by the National Institute of Environmental Health Sciences grant ES023675-01 (PI: Brian S. Schwartz) and training grant ES07141 (Sara G. Rasmussen). Additional support was provided by the National Science Foundation Integrative Graduate Education and Research Traineeship (Sara G. Rasmussen). No funders had input into the study design, conduct, data collection or analysis, or manuscript preparation. We declare that we have no conflicts of interest.

Author Contributions: Sara G. Rasmussen co-designed the study, conducted statistical analyses, created the figure, and prepared the first draft of the manuscript. Joan A. Casey co-designed the study, created exposure metrics, and provided critical revision of the manuscript. Karen Bandeen-Roche helped with study design, helped interpret results, and provided critical revision of the manuscript. Brian S. Schwartz co-designed the study, acquired the health data, helped interpret results, and provided critical revision of the manuscript.

Conflicts of Interest: The authors declare no conflict of interest. The founding sponsors had no role in the design of the study; in the collection, analyses, or interpretation of data; in the writing of the manuscript, and in the decision to publish the results.

\section{References}

1. Casey, J.A.; Kim, B.F.; Larsen, J.; Price, L.B.; Nachman, K.E. Industrial food animal production and community health. Curr. Environ. Health Rep. 2015, 2, 259-271. [CrossRef] [PubMed]

2. National Heart, Lung, and Blood Institute; National Asthma Education Program; Expert Panel on the Management of Asthma. Expert Panel Report 3: Guidelines for the Diagnosis and Management of Asthma: Full Report; U.S. Department of Health and Human Services, National Institutes of Health, National Heart, Lung, and Blood Institute: Bethesda, MD, USA, 2007.

3. Moorman, J.E.; Akinbami, L.J.; Bailey, C.M.; Johnson, C.A.; King, M.E.; Liu, X.; Zahran, H.S. National surveillance of asthma: United States, 2001-2010. Vital Health Stat. Ser. Anal. Epidemiol. Stud. 2012, 35, 1-58.

4. Casey, J.A.; Curriero, F.C.; Cosgrove, S.E.; Nachman, K.E.; Schwartz, B.S. High-Density livestock operations, crop field application of manure, and risk of Community-Associated Methicillin-Resistant Staphylococcus Aureus infection in Pennsylvania. JAMA Intern. Med. 2013, 173, 1980-1990. [CrossRef] [PubMed]

5. Loftus, C.; Yost, M.; Sampson, P.; Torres, E.; Arias, G.; Breckwich Vasquez, V.; Hartin, K.; Armstrong, J.; Tchong-French, M.; Vedal, S.; et al. Ambient ammonia exposures in an agricultural community and pediatric asthma morbidity. Epidemiology 2015, 26, 794-801. [CrossRef] [PubMed]

6. Johnston, N.W.; Sears, M.R. Asthma Exacerbations. 1: Epidemiology. Thorax 2006, 61, 722-728. [CrossRef] [PubMed]

7. Sigurdarson, S.T.; Kline, J.N. School proximity to concentrated animal feeding operations and prevalence of asthma in students. Chest 2006, 129, 1486-1491. [CrossRef] [PubMed]

8. Mirabelli, M.C.; Wing, S.; Marshall, S.W.; Wilcosky, T.C. Asthma symptoms among adolescents who attend public schools that are located near confined swine feeding operations. Pediatrics 2006, 118, e66-e75. [CrossRef] [PubMed]

9. Pavilonis, B.T.; Sanderson, W.T.; Merchant, J.A. Relative exposure to swine animal feeding operations and childhood asthma prevalence in an agricultural cohort. Environ. Res. 2013, 122, 74-80. [CrossRef] [PubMed]

10. Schinasi, L.; Horton, R.A.; Guidry, V.T.; Wing, S.; Marshall, S.W.; Morland, K.B. Air pollution, lung function, and physical symptoms in communities near concentrated swine feeding operations. Epidemiology 2011, 22, 208-215. [CrossRef] [PubMed]

11. Borlee, F.; Yzermans, C.J.; van Dijk, C.E.; Heederik, D.; Smit, L.A. Increased respiratory symptoms in COPD patients living in the vicinity of livestock farms. Eur. Respir. J. 2015, 46, 1605-1614. [CrossRef] [PubMed]

12. Radon, K.; Schulze, A.; Ehrenstein, V.; van Strien, R.T.; Praml, G.; Nowak, D. Environmental exposure to confined animal feeding operations and respiratory health of neighboring residents. Epidemiology 2007, 18, 300-308. [CrossRef] [PubMed] 
13. Schulze, A.; Rommelt, H.; Ehrenstein, V.; van Strien, R.; Praml, G.; Kuchenhoff, H.; Nowak, D.; Radon, K. Effects on pulmonary health of neighboring residents of concentrated animal feeding operations: Exposure assessed using optimized estimation technique. Arch. Environ. Occup. Health 2011, 66, 146-154. [CrossRef] [PubMed]

14. Smit, L.A.; Hooiveld, M.; van der Sman-de Beer, F.; Opstal-van Winden, A.W.; Beekhuizen, J.; Wouters, I.M.; Yzermans, C.J.; Heederik, D. Air pollution from livestock farms, and asthma, allergic rhinitis and COPD among neighbouring residents. Occup. Environ. Med. 2014, 71, 134-140. [CrossRef] [PubMed]

15. Van Dijk, C.E.; Garcia-Aymerich, J.; Carsin, A.E.; Smit, L.A.; Borlee, F.; Heederik, D.J.; Donker, G.A.; Yzermans, C.J.; Zock, J.P. Risk of exacerbations in copd and asthma patients living in the neighbourhood of livestock farms: Observational study using longitudinal data. Int. J. Hyg. Environ. Health 2016, 219, 278-287. [CrossRef] [PubMed]

16. Van Dijk, C.E.; Smit, L.A.; Hooiveld, M.; Zock, J.; Wouters, I.M.; Heederik, D.J.; Yzermans, C.J. Associations between proximity to livestock farms, primary health care visits and self-reported symptoms. BMC Fam. Pract. 2016, 17, 22. [CrossRef] [PubMed]

17. Rasmussen, S.G.; Ogburn, E.L.; McCormack, M.; Casey, J.A.; Bandeen-Roche, K.; Mercer, D.G.; Schwartz, B.S. Association between unconventional natural gas development in the marcellus shale and asthma exacerbations. JAMA Intern. Med. 2016, 176, 1334-1343. [CrossRef] [PubMed]

18. Pacheco, J.A.; Avila, P.C.; Thompson, J.A.; Law, M.; Quraishi, J.A.; Greiman, A.K.; Just, E.M.; Kho, A. A highly specific algorithm for identifying asthma cases and controls for Genome-Wide Association Studies. AMIA Annu. Symp. Proc. 2009, 2009, 497-501. [PubMed]

19. Ogden, C.L.; Carroll, M.D.; Kit, B.K.; Flegal, K.M. Prevalence of childhood and adult obesity in the United States, 2011-2012. JAMA 2014, 311, 806. [CrossRef] [PubMed]

20. Nau, C.; Schwartz, B.S.; Bandeen-Roche, K.; Liu, A.; Pollak, J.; Hirsch, A.; Bailey-Davis, L.; Glass, T.A. Community socioeconomic deprivation and obesity trajectories in children using electronic health records. Obesity 2015, 23, 207-212. [CrossRef] [PubMed]

21. Liu, A.Y.; Curriero, F.C.; Glass, T.A.; Stewart, W.F.; Schwartz, B.S. Associations of the burden of coal abandoned mine lands with three dimensions of community context in Pennsylvania. ISRN Public Health 2012. [CrossRef]

22. Casey, J.A.; Schwartz, B.S.; Stewart, W.F.; Adler, N.E. Using electronic health records for population health research: A review of methods and applications. Annu. Rev. Public Health 2015, 37, 61-81. [CrossRef] [PubMed]

(C) 2017 by the authors. Licensee MDPI, Basel, Switzerland. This article is an open access article distributed under the terms and conditions of the Creative Commons Attribution (CC BY) license (http:/ / creativecommons.org/licenses/by/4.0/). 